\section{The Whistle-Blower in Healthcare}

$\mathrm{H}$ ealthcare professionals who disclose risks to patients and healthcare organizations are often labelled whistleblowers. In the United States, "credible reports are that 85\% of whistle-blowers will suffer serious repercussions. In Canada, it's probably higher closer to 95\%" (Quinn 2006). The result is that patients and communities often end up losing their most passionate advocates, and healthcare loses valuable ethical and moral leadership.

This is not a new phenomenon. Semelweiss in 1850 faced severe opposition and criticism when he discovered that physician practices led to infections in childbirth. Dr. Nancy Oliveri of Toronto faced opposition, criticism and sanctions for disclosing concerns about the safety of a drug undergoing clinical trials. David Graham of the US Food and Drug Administration raised concerns about the safety of Vioxx (rofecoxib) and other drugs, and faced career sanctions. In Ottawa, Drs. Chopra and Haydon were sanctioned for their comments on mad cow disease (bovine spongiform encephalopathy). Most recently, it was felt to be necessary for the Campbell Commission on severe acute respiratory syndrome (SARS) in Ontario to grant "whistle-blower protection" and a promise of anonymity to encourage healthcare workers to give testimony in the investigation about the SARS outbreak in Toronto.

Dangerous practices, ineffective policies and marginal procedures in healthcare may lead to poor patient outcomes. As seen with SARS, contagious disease can spread rapidly from hospitals and immobilize entire healthcare systems and economies. Safety in the healthcare institution requires monitoring of the workplace as well as the continuous improvement of medical procedures and practices. With the reports of hospital-transmitted disease, such as SARS, and antibiotic-resistant bacteria being propagated into the general communities, hospital safety is becoming a public health issue.

Individual mistakes will occur in our complex health systems. A system responsive to feedback may correct mistakes before lasting damage occurs. In my experience, poor patient outcomes often are a consequence of a series of errors. Errors could become compounded if they are left to propagate through the system. Adverse individual patient outcomes may be viewed as indicators that policies and procedures or practices need to be reviewed and corrected.

Good communication, empowerment of front-line health professionals and continuous education are important elements of self-monitoring and self-correcting healthcare processes. They could lead to high-functioning learning organizations that operate in a state of continuous vigilance, looking for opportunities to improve.

There are risks when the clinical leaders and front-line workers who are proactive about risk management are called whistle-blowers. They are labelled as poor team players and are often isolated and subjected to harassment, threats and even career termination. A second outcome is that co-workers learn that the safest career path is silence and conformity. The third effect could be that a cascade of errors and breakdowns propagate until the consequences become too large to be contained within any single institution and spill out into the general community.

When an organization is faced with unusual or unexpected threats, conformity dictated by fear may lead to front-line workers being slow to pass information on to the managers. This could lead to either decision paralysis or poor decisions by management. It is in a crisis situation that a culture of empowerment of front-line staff is particularly important. Such empowerment could result in effective and timely organizational decision-making and when it is needed most.

Legislation focused on protecting whistle-blowers may prove ineffective if organizations still find ways to silence internal criticism. Whistle-blower legislation is often enforced retroactive to the event. It does not directly put the onus on management to create open and responsive policies that proactively establish best practices at all times. Such legislation does not protect the health professional who may recognize risks far ahead of the possible consequences. Processes need to be in place to independently investigate and act on concerns that are raised by staff who have the best intentions to safeguard our patients and communities.

Legislation should place organizational accountability at the board level for creating and monitoring a culture of empowerment for front-line workers and clinical leaders. Health professionals need to follow established internal procedures for identifying and reporting unsafe behaviours and practices. These procedures should ensure that concerns are dealt with transparently, without negative consequences to the individual who is acting in the best interests of patients and the public. The boards of our hospitals, along with senior management, need to be held accountable for establishing an open, honest and ethical environment.

Errors and adverse patient outcomes are opportunities for learning and continuous improvement for the entire healthcare team. Doctors, nurses and technologists must be encouraged to admit mistakes and monitor themselves, their peers and management. Part of the commitment to protect patients and the public should include the identification of risk, as well as the encouragement to voice concerns about the safety and relevance of our practices, policies and procedures in the workplace.

\section{Reference}

Quinn, P. 2006, April 19. “A Company's Best Defence.” National Post.

- Ronn Goldberg, MD, MBA, FRCPC, is adjunct professor, Faculty of Medicine (Medical Imaging), at the University of Toronto, and a lecturer, Schulich School of Business, Health Industry Management Program, at York University in Toronto, Ontario. 
Don't Look South for Answers: The Role of Cultural Imperatives in Canadian and US Healthcare

$\mathrm{M}$ edical anthropology is the study of medical systems of care and how they evolve within a defined culture. While much rhetoric has been heard comparing the Canadian and American healthcare systems, the critical role of culture has been largely ignored. One simply cannot compare these two systems without a thorough understanding and acknowledgement of their cultural milieux.

The US consumer is the ultimate value seeker, continually demanding cheaper, better products and services and expecting them immediately on demand. The baby boomers have driven the consumption economy since the 1950s, and now this group, 80 million strong, has the discretionary income to match its demands. This group is defined by a focus on maintenance of optimum health and independence. Significant rewards have been realized by those who can meet the expectations of this group.

As the boomers age, America will become a nation of savers not spenders, and will provide less in the way of taxes, with their reduced incomes. Reduced tax revenues will result in an underfunding of Medicare, and curtailed spending will result in a less robust economy, leading to reduced tax revenues from employed individuals and the companies they work for. At the same time, the baby boomers are going to begin to tap into the Medicare coffers to support their chronic illnesses. And yet, culturally, they will retain the expectations of high levels of service, immediate access and the use of expensive technology.

American culture is at present not accepting of tax increases, even to fund deficits in healthcare programs and services. It is this culture of entitlement that will soon bring America to a healthcare crisis of unimaginable scale, with no easy solution, precisely because culture tends to have inertia to it - moving a group away from a cultural centre point that is based on highly prized value sets can be extremely difficult.

Our Canadian culture, on the other hand, can be characterized by a love of freedom but tempered by a respect for other cultures and for each other. Canadians have traditionally accepted a higher tax rate with the expectation that there will be protection of our values, such as universal healthcare for all citizens, the support of new parents and access to all levels of education. Canadians believe in helping those less fortunate and are willing to pay for these social programs that provide the foundation for a "civil society."

US culture can therefore be described in terms of individualism (life, liberty and the pursuit of happiness), whereas Canadian culture can be described in terms of collectivism (peace, order and good government).

The Canadian consumer also has high demands of purveyors of goods and services, and we too have a baby boomer wave that will contribute less to the economy in 15 years than it does now. The central question must be this: In what ways can the Canadian culture, and by extension its healthcare system, respond to this pivotal demographic challenge, which is looming large on the horizon?

\section{Who Pays?}

Much has been made of the differences between the two healthcare systems in the debate around private versus public, but these differences must be placed in a cultural context. The insurer or health plan in the United States provides value to the health system in several ways. Fully two-thirds of the health plan or insurer clients are employers that are self-insured (i.e., they have taken on the full financial risk, but not the legal risk, of providing healthcare for their employees). For the other onethird of clients, the insurer or health plan takes the risk and therefore charges a margin. The health plan enrols members, pays medical claims, prints health cards, establishes networks of providers (doctors and hospitals) and also provides case management, chronic disease management and wellness programs all designed to keep the members as healthy as possible (thereby, reducing medical claim costs).

So, what about the huge uninsured segment of the population? As the US economy is slowing and healthcare costs continue to skyrocket, this segment of the population is growing. Not only are they unable to afford health coverage for themselves and their families, they are not providing the taxes that are needed to support their aging Medicare-enrolled parents.

Hospitals in the United States have, for many years, been mandated to accept all people who present themselves to emergency rooms, regardless of ability to pay. So, whether there is health plan coverage or not, the hospital is required to provide emergent and appropriate care. Over $90 \%$ of all hospitals in the United States are non-profit hospitals; they do not pay taxes. In exchange for this privilege, the hospitals must provide uncompensated care for the community. Yet, roll the clock forward 15 years, and it is very likely that the tidal wave of the uninsured may drown these same hospitals, forcing them to close their doors.

So, who pays? Ultimately, in both countries the individual pays; but in the United States, the role of the employer is significant and unique.

\section{Integration and Inefficiency}

In Canada, each province has adopted to some degree a system of local or regional "health authorities" that are charged with planning, funding and integrating healthcare to some extent. Every segment of the healthcare system operates at nearly $100 \%$ of capacity. There is little competition between providers, the unit price to the taxpayer is very low compared with that in 
the United States and the health human resources factor is controlled tightly. And although wait times and access are constant problems, the overall quality of care is arguably quite "good," or in cultural terms "acceptable to the group."

Efficiency in Canada will be achieved through the integration of providers and through a population-based approach to care provision. The backbone of integration will (eventually) be a secure electronic health record that follows the patient seamlessly from one medical information system to another.

In the US healthcare system, integration is legally, economically and culturally impossible. Integration currently occurs within discrete hospital health systems, where a single corporate board of directors oversees several hospitals in a region, as well as owned home health agencies, long-term care centres and physician groups. Each hospital health system is vertically integrated but competes with other vertically integrated hospital health systems within the same market. Without the ability to integrate, the gross inefficiencies inherent in the US healthcare system can only become worse as the pressures placed on it continue to rise.

\section{Macroeconomic Factors}

There are a number of emerging trends in Canada and the United States that have a direct impact on how each country deals with the economic realities of healthcare provision. The economies of each country are certainly linked, yet the cultural differences between them have shaped the policies that have been adopted through their histories.

Each country has its own unique foreign policy strategy, for example, that is acceptable to its citizens (voters) and requires a certain and significant financial commitment. Likewise, each country has its own policies around funding and distribution of social programs that must be acceptable to its citizens within a framework defined by cultural boundaries.

While both countries are politically stable, unlike Canada, the United States must deal with the costs of certain geopolitical risks. The expense of sustaining military forces in multiple (overseas) theatres is a significant drain on the US gross national product, in addition to the increasing costs of providing homeland security. These financial pressures have a direct impact on the ability to support healthcare initiatives. As the only industrialized nation in the world that does not provide access to complete healthcare coverage for its citizens, the United States is heavily dependent on its private healthcare industry to meet the medical needs of its population. The aging demographic is applying an undeniable pressure on the existing economy, so without dramatic changes, the collapse of Medicare and social security is inevitable. The US government only funds $35-40 \%$ of the cost of providing healthcare; therefore, without restructuring, it currently has only a limited ability to control outcomes.

The trillion-dollar US deficit is another macroeconomic hurdle that must be considered. The deficit is expected to grow unless trends are managed aggressively, something the current (transitioning) administration is unlikely to do. The United States is being forced to finance the debt owed to nationals in countries other than the United States. The debt service impact on the US economy will therefore become unprecedented, allowing for less latitude in funding for the healthcare sector.

Another macroeconomic trend that has affected the United States more significantly than Canada is the third-party equity shift away from the healthcare sector to the more lucrative energy and metals sectors. Reduced capitalization has a direct impact on the for-profit entities in healthcare, and their necessary response is to increase unit prices, constrain services and delay payments to providers.

Add to this pressure the fact that the United States is a net consumer of energy, whereas Canada is a net producer. As energy resources begin to constrict as a restricted asset, the United States will endure increasing input costs that will make it less competitive in the long run. Canada, however, has a robust economy, with little debt, and its fiscal house in order, with adequate government controls in place. It is able to more effectively deal with the fiscal realities of healthcare provision in an integrated way, although not without the influence of political vagaries.

Nations have choices. How their elected leaders respond to the macroeconomic trends of the day is largely driven by the culture of the day. Choices are made based on the values that a nation holds dear.

So it is that healthcare choices are made very differently in Canada than in the United States. And, therefore, Canadians cannot look south for answers to concerns about aspects of healthcare provision in Canada. It is not so much because of the sanctity of the Canada Health Act or the legalistic concerns raised by the Chaoulli decision or the economic arguments put forward by ministers of health. Rather, it is because of the simple fact that health systems are a reflection of the culture in which they are found and, as such, imported solutions are untenable. There is no shortcut to finding a culturally acceptable solution to the challenges of the Canadian, or any other, healthcare system. Solutions must be homegrown.

\section{- Peter Nord, MD, is vice-president, medical affairs and chief of staff for Providence Healthcare in Toronto. Prior to joining Providence Health, he was physician and executive administrator within the Sentara Healthcare System in the U.S. Before that, Dr. Nord was president and chief medical officer of The Flying Hospital, Inc., a worldwide non-profit humanitarian organization that brings free medical and surgical care to people in need.}

About the Cover: Complex care is about interaction, collaboration, commitment, skills, leadership, coaching, challenges, process and more. But most importantly it is about care. The cover is a gentle reminder that, above all, this is about people as patients and people as providers - each with their own special complexities. 